\title{
Introduction to the Special Issue on Government and Social Media
}

The rise of social media offers governments at different levels and localities access to a variety of platforms and tools for public administration and for interaction with citizens and constituent organizations. Social media also support and facilitate citizens' and organizations' interactions with each other in efforts to share information and communicate about issues of interest, collective problem solving, and democratic governance. Studies of the use and impact of social media are part of the area of computing research known as social computing; that is, the intersection of social behavior (e.g., political science, psychology, communication, sociology, economics) and computational systems and software (e.g., computer science). The study of government, public administration, democracy, and technology is rooted in these disciplines. The benefits of the communication technology of social media derive from their affordances for direct communication, empowerment, and crowdsourcing among users in response to routines of daily life, as well as to big challenges, such as long-term municipal planning, regional and global environmental crises, and social change.

By means of social media, channels such as micro-blogs (e.g., Twitter), social network sites (e.g., Facebook, LinkedIn), and other user-generated content and mark-up tools, governments, citizens, businesses, and voluntary associations share information, ask questions, and compete or collaborate on problem-solving within and among neighborhoods, industries, states, and nations. Social media are used, among other channels, to broadcast information, promote perspectives and policies, and to garner (or sometimes disrupt) support for collective action. The staggering number and diversity of messages and topics generated by users make it difficult for all entities-government, organizations, citizens-to process and make sense of vast amounts of disparate and unstructured information, images, and sentiments, especially for non-technical users. Analyses of communication behavior (such as information sharing), trends, and message content by all parties should help contribute to our knowledge of the ways the use of social media are affecting collective problem-solving, public administration, and social structures. Empirical research of actual use of social media contributes to our understanding of the challenges and benefits of social media use in the public domain.

In their article titled "MPs on FB: Differences between members of coalition and opposition," authors Nili Steinfeld and Azi Lev-On analyze the content of the Facebook (FB) pages of all members of the $19^{\text {th }}$ Israeli Parliament or Knesset (2013-15). They find differences in communication behavior between coalition and opposition MPs on multiple measures, including: scope of publication, scope of user engagement, content, and format.

Authors Loni Hagen, Stephen Neely, Ryan Scharf, and Thomas Keller examine the use of Twitter for crisis communications in their article "Government Social Media Communications during Zika Health Crisis: An Analysis of Federal, State, and Local Level Governments.” The authors focus on public actors' use of Twitter

CCS Concepts: • Human-centered computing $\rightarrow$ Empirical studies in HCI;

Additional Key Words and Phrases: Conversation, Facebook, police agency, public comment, dialogic accounting, case study

ACM Reference format:

Andrea Kavanaugh, Rodrigo Sandoval-Almazan, and Jolien Ubacht. 2020. Introduction to the Special Issue on Government and Social Media. Digit. Gov.: Res. Pract. 1, 2, Article 10 (April 2020), 3 pages.

https://doi.org/10.1145/3381940

(c) 2020 Copyright held by the owner/author(s).

2639-0175/2020/04-ART10

https://doi.org/10.1145/3381940

Digital Government: Research and Practice, Vol. 1, No. 2, Article 10. Publication date: April 2020. 
during the 2016 Zika virus outbreak in the United States. They find that engaging with elected officials is an effective strategy, particularly for state and local government agencies that do not have a strong presence on social media. Thus, public agencies can leverage the larger follower networks enjoyed by elected officials to ensure the timely and effective communication of critical messages.

Qunfang Wu and Yun Huang study the use of Facebook by 43 US municipal police agencies and the public in their article "Towards Supporting Dialogic Accounting for Conversations between Police Agencies and Public on Facebook." The authors analyze close to 30,000 posts by police and 628,000 public comments. They find that a minuscule number (less than 1\%) of public comments received a reply from the police agencies; those replies were mainly in response to information-seeking requests. Further, police agencies typically ignored negative comments.

Authors Ussama Yaqub, Nitesh Sharma, Rachit Pabreja, Soon Ae Chun, Vijay Atluri, and Jaideep Vaidya investigate polarization and subjectivity constructs in Twitter using location data in their article "Humor, Support, and Criticism: An Analysis and Visualization of Subjectivity and Polarity of Twitter Location Data." They perform sentiment analysis on Twitter data by location extracted from tweet metadata related to the 2016 US Presidential election and the 2017 UK general election as case studies. The authors examine similarity in tendencies of sentiment towards political candidates and parties in the two datasets to generalize results. Findings highlight the similarities in user sentiment during elections on Twitter regardless of the methodology employed to gather and download data.

In their article "Analyzing and Visualizing Government-citizen Interactions on Twitter to Support Public Policy-making," authors Rocio Huber, Elsa Estevez, Ana Maguitman, and Tomasz Janowski present a Twitter analytics tool they developed called Twitter Analytics for Government Intelligence and Public Participation (TA4GIP). TA4GIP software analyzes sentiment in tweets and presents the results in visualizations for nonexperts, such as policy-makers and government representatives, as well as the public. The authors test and evaluate their tool with Twitter posts from five government ministries in Mexico and corresponding citizen responses over a nine-month period during 2017-2018. The evaluation of the TA4GIP tool shows that it is effective in identifying, analyzing, and representing abnormal activity, salient topics, correlations between tweets and types of emotional response, and polarization patterns in citizen response to given topics. This type of tool should help non-expert users-whether government or citizen or other-to make sense of large data collections and to base further deliberation and collective problem-solving on increased understanding of the perspectives of participating parties.

The analysis of emoticons is the focus of the study by Rodrigo Sandoval-Almazan and David Valle Cruz titled "Sentiment Analysis of Facebook on Political Campaigns." The authors identify and classify emoticons posted by government and citizen users in over 4,000 FB posts related to a local government election campaign over several months in 2017 in the state of Mexico in central Mexico. Using a classification model for emoticons, the authors categorize emoticons appearing in the Facebook pages of political candidates and citizen respondents in a test of the relationship between sentiment toward candidates and election outcomes.

The computing machine has brought about many changes in societies, including the ways that citizens govern themselves and how governments function. As the technology critic Roderick Seidenberg wrote as far back as 1950 in Post-historic Man (p. 174), "it has been said that the fundamental question of our era is the problem of integrating freedom with planning." This fundamental question is no less paramount today, at the outset of the 21st century. The types of machines have evolved since the mid-20th century, but their inherent tendency toward integration and coordination persist. Insofar as computing machines affect the structure of society, we seek to understand through studies such as the ones offered in this issue, how social computing is changing governments and citizens and how societies are reacting to these transformations and disruptions brought by social media.

There is no doubt that social media change the ways that governments interact with citizens and its constituent organizations. This transformation leads to new opportunities for interactions and information sharing. However, problems such as the overwhelming number of messages, images, and other posts that arrive daily at

Digital Government: Research and Practice, Vol. 1, No. 2, Article 10. Publication date: April 2020. 
public offices where few know how to respond to or make sense of them can lead to misalignment with citizens' and other constituents' expectations. The research in this issue requires our vigilance and continued attention to these challenges and offers insights and findings that reveal potential and actual imbalances in society that undermine human agency and threaten freedom of speech, the public interest, and a well-informed citizenry.

This special issue features a selection of six papers from the Research Track called Government and Social Media, of the 19th Annual International Conference on Digital Government Research (dg.o 2018). The papers selected for this special issue have been revised, updated, and expanded. They are all firmly grounded in data

from empirical cases and represent the state-of-the-art in social media data analytics. Half of the articles focus on Twitter, the other half on Facebook; most of the articles analyze government use of these media, and several focus on government-citizen interactions. They use qualitative and/or quantitative methods to analyze sentiment, visualize data, or track trends and patterns. They contribute to knowledge in the areas of computational analysis, public policy, social and political participation, governance, and public administration.

\section{REFERENCES}

Seidenberg Roderick. 1950. Post-historic Man. Chapel Hill, NC: University of North Carolina Press.

Andrea Kavanaugh

Rodrigo Sandoval-Almazan

Jolien Ubacht

Guest Editors 